\title{
Isolated Left Ventricular Noncompaction in a 25 Year Old Male
}

\begin{abstract}
Albert T Pochury ${ }^{1}$, Patrick R Marak ${ }^{2}$, Johan Vanlalpeka ${ }^{3}$
Abstract: Ventricular noncompaction (VNC) of the myocardium is a rare genetic cardiomyopathy caused by a disorder during endocardial morphogenesis and could be accompanied by life-threatening complications. The major clinical manifestations of VNC are heart failure, arrhythmias, and embolic events. The left ventricle is the most commonly reported affected site, but a few cases of right ventricular involvement have also been reported. We report the case of a young male who presented with features of heart failure. Trans thoracic echocardiography showed the characteristic trabeculations of left ventricular noncompaction with associated depressed left ventricular dysfunction.
\end{abstract}

Keywords: ventricular noncompaction, spongiform cardiomyopathy

\section{Introduction}

Ventricular noncompaction (VNC) of the myocardium is a rare genetic cardiomyopathy that is believed to arise from arrested endomyocardial development during embryogenesis [1]. It is characterised by the presence of deep intertrabecular recesses in the hypertrophied, frequently hypokinetic segment of ventricular myocardium[2,3]. Myocardial noncompaction can occur in isolation or in association with cardiac syndromes or disease[4]. Myocardial noncompaction can occur at any age; the clinical presentation is nonspecific and varies from no symptoms to conduction defects, thromboembolism, ventricular arrhythmias, severe heart failure, or sudden cardiac death[5,6]. Here we report the case of a young male who presented with features of heart failure

\section{Case Report}

A 25 year old male presented at our institutions emergency department with progressive shortness of breath associated with episodes of palpitations which were present on exertion but was relieved on resting. He did not have other cardiac symptoms like anginal pain, syncopal attacks, orthopnoea or paroxysmal nocturnal dyspnoea. He was a non-smoker, nonalcoholic, normotensive and non-diabetic. There was no history of sudden cardiac death in any of the family members

Physical examination revealed only a $2 / 6$ systolic ejection murmur which was loudest at the left midsternal border on cardiac auscultation. The laboratory results were within normal limits. Electrocardiogram (ECG) showed sinus rhythm with regular rate.

Trans thoracic echocardiography revealed a trabeculated, sponge-like appearance of the left ventricle, more affecting the inferior posterior wall. There were associated moderate tricuspid valve regurgitation, mild pericardial effusion with moderate left ventricular systolic dysfunction. The left ventricular ejection fraction was $32 \%$ only. Cardiac magnetic resonance imaging showed the same trabeculation pattern in the left ventricle. These findings let to the diagnosis of left ventricular noncompaction.

\section{Discussion}

VNC of the myocardium is a rare genetic cardiomyopathy. The left ventricle is more frequently involved with biventricular involvement rarely encountered. [7,8]. Oechslin et al.[7] demonstrated in a follow-up study of 34 patients that the most important clinical manifestations of VNC were heart failure $(53 \%)$, ventricular tachycardia $(41 \%)$, sudden cardiac death $(35 \%)$, syncope $(18 \%)$, and embolic events $(24 \%)$.

Among all the presenting symptom of VNC, the most common reason for referral was heart failure, [ 7] with onethird of these patients having NYHA class III/IV at time of diagnosis [9]. Both systolic and diastolic dysfunction can develop. Systolic dysfunction and arrhythmias might be secondary to microcirculatory dysfunction and subepicardial hypoperfusion[10]

Echocardiography is crucial for the diagnosis of LVNC. Widely accepted diagnostic criteria [11] include the following:

1) An excessively thick myocardial wall structure in 2 differing layers - a thin, compacted epicardial layer and a thicker, noncompacted endocardial layer

2) A characteristic end-systolic ratio of $>2: 1$ for noncompacted-to-compacted wall thickness

3) Prominent multiple, chiefly intracavitary trabeculae, with color-Doppler echocardiographic evidence of communication between the deep intertrabecular recesses and the ventricular cavity

4) No cardiac abnormalities beyond the above, in isolated noncompaction cases.

Our patient presented with features of heart failure along with associated palpitations with trans thoracic echocardiography showing features consistent with left ventricular noncompaction. In patients with LVNC, treatment options vary on an individual basis, ranging from medical management in mild cases to heart transplantation in patients with refractory symptoms. Monitoring asymptomatic patients is encouraged, whether diagnosis is incidental or the consequence of familial screening, because of possible future complications in those individuals[5,6]. Our patient responded well to medical therapy. 


\section{International Journal of Science and Research (IJSR) \\ ISSN (Online): 2319-7064}

Index Copernicus Value (2013): 6.14 | Impact Factor (2014): 5.611

\section{Conclusion}

VNC is an uncommon disorder accompanied by lifethreatening complications. Its unusual presentation highlights the importance of a complete and thorough workup of patients presenting with apparently noncardiac symptom(s). Data is limited on specific therapy for VNC, but it is recommended that medical management be tailored towards the clinical manifestations, and standard guidelines should be applied for patients with reduced LVEF, and heart failure with preserved systolic function [12], in the setting of VNC. Patients with VNC, who meet standard criteria for anticoagulation, should also be managed according to standard guidelines [13].

\section{References}

[1] Freedom RM, Yoo SJ, Perrin D, Taylor G, Petersen S, Anderson RH. The morphological spectrum of ventricular noncompaction. Cardiol Young. 2005; 15:345-364.

[2] Richardson P, McKenna W, Bristow M. Report of the 1995 World Health Organization/International Society and Federation of Cardiology Task Force on the definition and classification of cardiomyopathies.Circulation. 1996;93:841-842.

[3] Chin TK, Perloff JK, Williams RG, Jue K, Mohrmann R. Isolated noncompaction of left ventricular myocardium. A study of eight cases. Circulation 1990;82(2):507-13.

[4] Jenni R, Oechslin E, Schneider J, Attenhofer Jost C, Kaufmann PA. Echocardiographic and patho-anatomic characteristics of isolated left ventricular noncompaction: a step towards classification as a distinct cardiomyopathy. Heart. 2001;86:666-671.

[5] Greutmann M, Mah ML, Silversides CK, Klaassen S, Jost CH, Jenni R, Oechslin EN. Predictors of adverse outcome in adolescents and adults with isolated left ventricular noncompaction. Am J Cardiol 2012;109(2):276-81

[6] Bhatia NL, Tajik AJ, Wilansky S, Steidley DE, Mookadam F. Isolated noncompaction of the left ventricular myocardium in adults: a systematic overview. J Card Fail 2011;17(9):771-8.

[7] Oechslin EN, Attenhofer Jost CH, Rojas JR, Kaufmann PA, Jenni R. Long-term follow-up of 34 adults with isolated left ventricular noncompaction: a distinct cardiomyopathy with poor prognosis. Journal of the American College of Cardiology. 2000;36(2):493-500.

[8] Duru F, Candinas R. Noncompaction of ventricular myocardium and arrhythmias. Journal of Cardiovascular Electrophysiology. 2000;11(4):p. 493. 9. Jenni R, Oechslin EN, Van Der Loo B. Isolated ventricular non-compaction of the myocardium in adults.Heart. 2007;93(1):11-15.

[9] Bhatia NL, Tajik AJ, Wilansky S, Steidley DE, Mookadam F. Isolated noncompaction of the left ventricular myocardium in adults: a systematic overview. J Card Fail 2011;17(9):771-8.

[10] Jenni R, Oechslin EN, van der Loo B. Isolated ventricular non-compaction of the myocardium in adults. Heart 2007;93 (1):11-5
[11]Hunt SA, Abraham WT, Chin MH, et al. 2009 focused update incorporated into the ACC/AHA 2005 guidelines for the diagnosis and management of heart failure in adults: a report of the american college of cardiology foundation/american heart association task force on practice guidelines: developed in collaboration with the international society for heart and lung transplantation. Circulation. 2009;119:e391-e479.

[12] Stöllberger C, Blazek G, Dobias C, Hanafin A, Wegner $\mathrm{C}$, Finsterer J. Frequency of stroke and embolism in left ventricular hypertrabeculation/noncompaction. American Journal of Cardiology.2011;108(7):10211023. 